\title{
Multiple secondary cauda equina non- Hodgkin's lymphoma: a case report and literature review
}

\author{
Yunchao Ban, Zhitao Jing and Jingyu Zou*
}

\begin{abstract}
Background: Secondary central nervous system involvement of non-Hodgkin's lymphoma (NHL) is rare and with poor prognosis, the most common pathological type is diffuse large B cell lymphoma (DLBCL). Although it can occur in any part of central nervous system, it rarely directly infiltrates the spinal cord or cauda equina.

Case presentation: We present the case of 64-year-old immunocompetent man with a worsening pain of waist and left lower extremity, accompanied by numbness and paresis of bilateral lower extremity for 20 days. His previous medical history included a resection of painless mass in the left groin in another hospital 7 months ago, and the pathological diagnosis was non-Hodgkin small B cell lymphoma. Gd-enhanced MRI and F-18 FDG PET-CT scan demonstrated multiple infiltrations in the cauda equina. During the operation, we removed as many as 11 subdural-extramedullary bean-size lesions involving multiple nerve roots. The paralysis of his left leg recovered rapidly after the operation. During the follow-up period of more than one year, he underwent standard R-CHOP chemical therapy, no evidence of recurrence was noted until the 13th month, the patient died because of intracranial relapse.
\end{abstract}

Conclusions: Imaging examination is important in the diagnosis of multiple secondary cauda equina nonHodgkin's lymphoma, and we highlight the significance of gadolinium-enhanced MRI and F-18 FDG-PET/CT in preoperative diagnosis as well as the previous history.

Keywords: Lymphoma, Non-Hodgkin, Cauda equine

\section{Background}

Central nervous system lymphoma (CNSL), including primary central nervous system lymphoma (PCNSL) and secondary central nervous system lymphoma (SCNSL) constitute $1-6 \%$ central nervous system malignant tumors $[1,2]$. Up to $10 \%$ patients with non-Hodgkin's lymphoma may progress CNS infiltrations with poor prognosis, and large diffuse B-cell lymphoma is the most common pathological type [3-6]. Although SCNSL could occur in any part of central nervous system, it mostly affects the brain, then leptomeninge, eyes and spinal cord. Primary or secondary lymphoma of cauda equina is extremely rare. In a large study of 150 cauda equina tumors the incidence of lymphomas was 1.3\% [7]

\footnotetext{
* Correspondence: byc1664@163.com

Department of Neurosurgery, The First Affiliated Hospital of China Medical University, Nanjingbei street 155, Heping District, Shenyang, China
}

and over the years only a few case reports of primary cauda equina lymphoma have been published [8-10]. We present here a case of large diffuse B-cell lymphoma in the cauda equina, as well as a brief review the current literatures.

\section{Case presentation}

A 64-year-old immunocompetent man presented to the outpatient clinic of Department of Neurosurgery, complained of a worsening pain of waist and left lower extremity, accompanied by numbness and paresis of bilateral lower extremity for 20 days. 7 months before admission, he took a biopsy of left groin mass, the pathological diagnosis was non-Hodgkin small B cell lymphoma. Immunohistochemical staining demonstrated the typical cells with CD5(+), CD20(-), Pax-5(+), Bcl2(+), CD3(+), CD23(-), CyclinD-1(-), Ki-67(+> 50\%). According to the diagnosis, he underwent a standard 
CHOP chemical therapy immediately, and got a partial remission during the following 7 months, inguinal lymph nodes regressed by more than $50 \%$ and no new enlarged lymph node was detected by ultrasound examination. About 10 days after the last $\mathrm{CHOP}$, he got a persistent pain in the waist and left thigh, accompanied by numbness and paresis, the symptoms had rapidly progressed to both lower extremity and left him wheelchair bound in 20 days, then he came to our department for further treament.

Physical examination demonstrated spastic paralysis of the left lower limb and hypesthesia of bilateral lower limb under L4 level, he also got tendon hyperreflexia and Babinski sign positive in the left side, with bladder dysfunction.

Before admitted to our hospital, he took a whole-body F-18 FDG-PET/CT scan, which showed L3 level intrathecal FDG high uptake(Fig. 1a,b,d,e,g,h), without abnormal FDG uptake of other parts of central nervous system and the rest of the body, suggested probable involvement of lower spinal cord. Lumbar Gd-enhanced MRI showed L3 level multiple intrathecal lesions with isointense on T1WI and hypointense on T2WI, with remarkable homogenous enhancement. The total size of the lesions was about $2.29 * 1.39 \mathrm{~cm}$ with clear border, cauda equina was compressed badly. In the image of F18 FDG-PET/CT, only 2 nodules could be distinguished, but in the high resolution MRI, especially T2WI image, we could distinguish as many as 7 (Fig. 1a-i).

In consideration of the previous history, physical and image examination, we got a pre-operation diagnosis of secondary cauda equina lymphoma. A spinal canal decompression and tumor resection was performed 2 days after admission because the symptoms progressed rapidly, the patient developed complete paralysis and acute urinary retention. During the operation, we found the cauda equina was swollen and compressed badly, as many as 11 subdural-extramedullary bean-size nodules involving several nerve roots were found (Fig. 2). The nodules were red and with complete capsule, the relationship of tumors and cauda equina were too close to dissect, so we had to cut off the involved nerve roots to remove all the 11 nodules.

The paralysis of his left leg recovered rapidly since the operation, at the second day after operation, muscle strength was grade 2 , and at the 7 th day after operation, the patient could stand with assistance, only mild hypesthesia of the left leg remained. Post-operation MRI + C showed complete resection of the lesions with sufficient decompression. Pathological diagnosis was

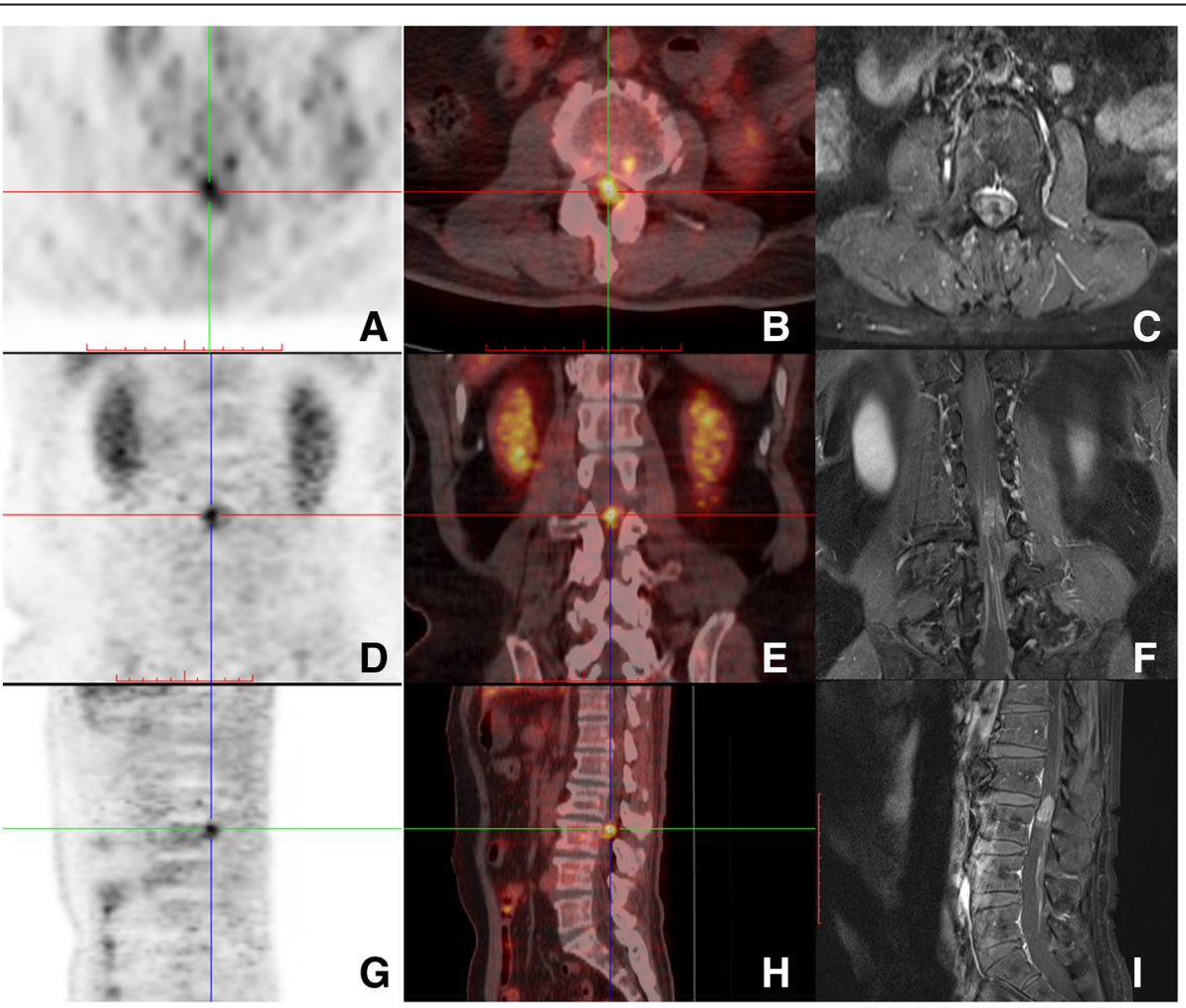

Fig. 1 F-18 FDG-PET/CT and Gd-enhanced MRI images in axial, coronal and sagittal views. a,b,d,e,g,h show intrathecal high uptake of FDG at the $L 3$ level. c,f,i show intrathecal mass of cauda equine at the $L 3$ level with remarkable homogenous enhancement, several isolated modules can be distinguished in axial, coronal and sagittal views, cauda equina was compressed 


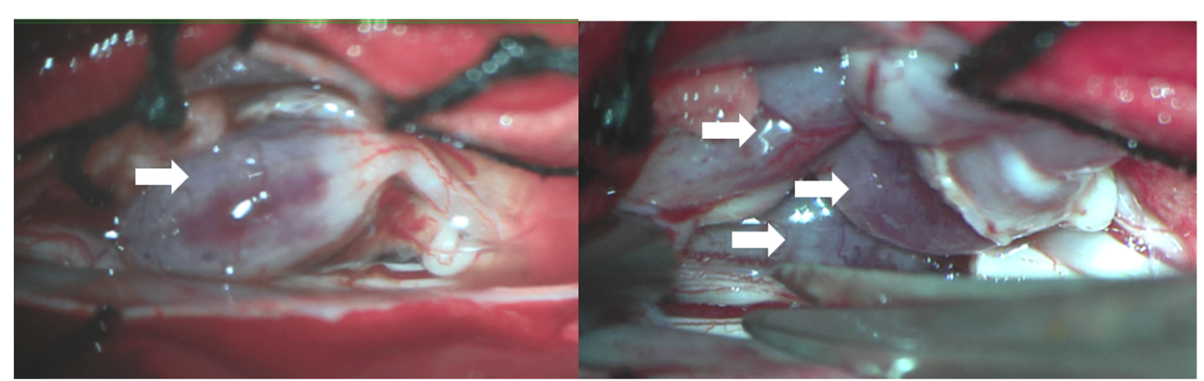

Fig. 2 Images during the operation through microscope (Leica M525 F40, 8x) showed cauda equine roots enlargement, several isolated bean-size lesions with complete capsule involving nerve roots (arrows)

diffuse large B cell lymphoma, immunohistochemical stain showed CD20(+), Pax-5(+), CD3(+/-), Vimen$\operatorname{tin}(+), \mathrm{NeuN}(-)$, CD99(-),GFAP(-), S-100(-), Ki-67(+ > 50\%), CK(-), CD56(-) Synaptophysin(-), TIF-1(-). The patient was transferred to the department of hematology at the 14th day after operation for further R-CHOP chemotherapy.

During the follow-up period of more than one year since the operation, the patient went on standard R$\mathrm{CHOP}$ chemical therapy. He got a partial bladder function recovery at the 4th week after the operation, and could walk slowly without assistance by then, no new symptom of spinal cord was detected. A lumbar MRI + $C$ at the 9th month showed no evidence of recurrence in situ (Fig. 3p-r). But at the 13th month, he visited the emergence room with severe headache and vomit, he was in such a bad condition that he was unable to stand MRI or F-18 FDG-PET/CT. Enhanced CT showed giant mass in bilateral frontal lobes with remarkable homogenous enhancement, circled by extensive brain edema, which obviously meant recurrence of the NHL. The patient and his family refused any further treatment, and finally he died in the following 2 weeks because of brain herniation.

\section{Conclusions}

The incidence of central nervous system infiltration in system lymphoma varies between 10 and $20 \%$, and indicating a poor prognosis [11]. Diffuse large B cell lymphoma is the most common type of non-Hodgkin lymphoma, and the incidence of its infiltration in central nervous system is about 1.1 to $10.4 \%$ [4, 12, 13]. A previous database study of 605 newly diagnosed DLBCL patients who had not undergone CNS prophylaxis showed that the probability of secondary CNS involvement at 1 year after diagnosis was $4.5 \%$ [14]. The prognosis of patients experiencing secondary CNS involvement, especially during progression or after relapse of systemic lymphoma is extremely poor $[14,15]$. Spinal cord, especially cauda equina lymphoma is rarely reported.
In our case, the immunocompetent patient had normal lymphocyte count and fraction in peripheral blood, the diagnosis before operation was concluded from the previous biopsy history, symptoms, physical examination and radiography. He got a rapid progressing cauda equina syndrome in such a short time that we had to perform a total tumor resection instead of biopsy in hope of saving his motor ability, and fortunately his paralysis got recovery after the operation. Interestingly, the pathological diagnosis was non-Hodgkin small B cell lymphoma when he had the inguinal lymph node mass, but 7 months later, it transformed into diffuse large B cell lymphoma, that may suggest progressing of the disease. In the follow up period, the patient kept on standard R-CHOP treatment without any evidence of in situ relapse, until the 13th month he got a severe relapse in bilateral front lobes and eventually causing death. The course of the relapse was so short that we wondered if the malignancy grade of NHL progressed higher.

Flangan et al. [16] described the MRI feature of primary intramedullary spinal cord lymphoma, including multiple infiltration, enhancement, and cauda equina involvement. Suzuki et al. [17] summarized the MRI image findings of 23 cases of primary cauda equine lymphoma, the features of MRI are enlargement of the cauda equina with iso- or low intensity relative to the spinal cord signal on both T1WI and T2WI and the presence of enhancement of the cauda equina on contrast. In our case, lumbar Gd-enhanced MRI showed L3 level cauda equina enlargement, isolated lesions with isointense on T1WI and hypointense on T2WI and homogenous enhancement on contrast.

F-18 FDG-PET/CT plays an important role in monitoring and detecting relapses in malignant lymphoma patients, it is usually more sensitive than MRI in cranial nerves, nerve roots, and the cauda equina [18]. In our case, F-18 FDG-PET/CT excluded the possibility of involvement in other parts of the whole body especially CNS, so a surgical intervention could be considered; high resolution Gd-enhanced MRI demonstrated cauda equine roots involvement with severe compression in 


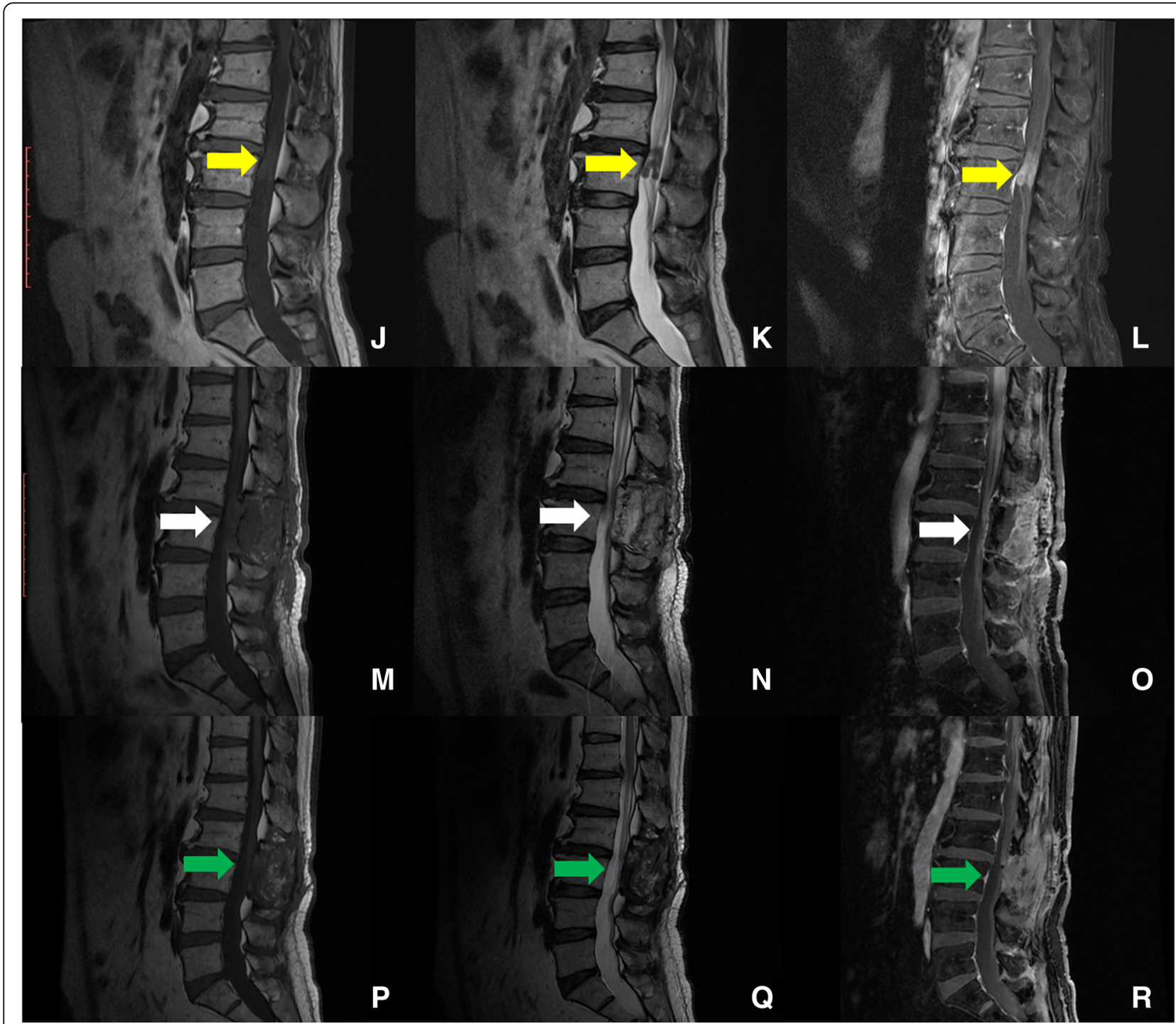

Fig. $3 \mathrm{MRI}$ images in sagittal sequence before operation showing isointense on T1WI (j) and hypointense on T2WI(k), with remarkable homogenous enhancement( $(\mathbf{I}) .4$ days $(\mathbf{m}, \mathbf{n}, \mathbf{o})$ and 9 months( $\mathbf{p}, \mathbf{q}, \mathbf{r})$ post-operation MRI showing totally resection of the tumors in corresponding sequences. The yellow arrows point to the tumor, the white and green arrows showed totally tumor resection with disappearance of enhancement

the L3 level, so we made a decision to resect all the tumors instead of biopsy. The resolution of MRI is much better than F-18 FDG-PET/CT, 7 of the lesions were detected in MRI vs only 2 in F-18 FDG-PET/CT. The intraoperative findings were consistent with the imaging performance, as many as 11 lesions were found and removed. According to our experience we recommend the combination of MRI and F-18 FDG-PET/CT in this kind of patients, it is effective not only for the diagnosis but also for surgery planning.

\section{Abbreviations}

CNSL: Central nervous system lymphoma; DLBCL: Diffuse large B cell lymphoma; NHL: Non-Hodgkin's lymphoma; PCNSL: Primary central nervous system lymphoma; SCNSL: Secondary central nervous system lymphoma

\section{Acknowledgements}

Not applicable.

\section{Authors' contributions}

$\mathrm{ZJ}$ and YB performed the operation, YB designed the study, collected the clinical data, and wrote the paper, JZ collected the imaging data including F-18 FDG-PET/CT and the follow-up data. All authors were involved in the revision of the manuscript and have approved the final version.

\section{Funding}

No funding was received for this research.

Availability of data and materials

The datasets used and analysed during the current study available from the corresponding author on reasonable request. 


\section{Ethics approval and consent to participate}

This case report was approved by the ethics committee of The First Affiliated Hospital of China Medical University. The authors obtained patient's written informed consent to participate.

\section{Consent for publication}

The authors declare that the patient gave written consent for publication.

\section{Competing interests}

The authors declare that they have no conflicts of interest.

Received: 6 November 2018 Accepted: 6 June 2019

Published online: 17 June 2019

\section{References}

1. Jellinger KA, Paulus W. Primary central nervous system lymphomas--an update. J Cancer Res Clin Oncol. 1992;119:7-27.

2. Ling SM, Roach M, Larson DA, Wara WM. Radiotherapy of primary central nervous system lymphoma in patients with and without human immunodeficiency virus. Ten years of treatment experience at the University of California san Francisco. Cancer. 1994;73:2570-82.

3. Haioun C, Besson C, Lepage E, Thieblemont C, Simon D, Rose C, Tilly H, Sonet A, Lederlin P, Attal M, Brière J, Reyes F. Incidence and risk factors of central nervous system relapse in histologically aggressive non-Hodgkin's lymphoma uniformly treated and receiving intrathecal central nervous system prophylaxis: a GELA study on 974 patients. Groupe d'Etudes des Lymphomes de l'Adulte. Ann Oncol. 2000;11:685-90.

4. Hollender A, Kvaloy S, Nome O, Skovlund E, Lote K, Holte H. Central nervous system involvement following diagnosis of non-Hodgkin's lymphoma: a risk model. Ann Oncol. 2002;13:1099-107.

5. Nagpal S, Glantz MJ, Recht L. Treatment and prevention of secondary CNS lymphoma. Semin Neurol. 2010;30:263-72.

6. Kim SJ, Oh SY, Kim JS, Kim H, Lee GW, Won JH, Shin HJ, Yang DH, Choi CW, Park J, Kim WS, Suh C. Secondary central nervous system (CNS) involvement in patients with diffuse large B-cell lymphoma: a therapeutic dilemma. Ann Hematol. 2011;90:539-46.

7. Wippold FJ, Smirniotopoulos JG, Pilgram TK. Lesions of the cauda equina: a clinical and pathology review from the armed forces Institute of Pathology. Clin Neurol Neurosurg. 1997:99:229-34.

8. Zagami AS, Granot R. Non-Hodgkin's lymphoma involving the cauda equina and ocular cranial nerves: case reports and literature review. J Clin Neurosci. 2003;10:696-9

9. Nishida H, Hori M, Obara K. Primary B-cell lymphoma of the cauda equina, successfully treated with high-dose methotrexate plus high-dose cytarabine: a case report with MRI findings. Neurol Sci. 2012;33:403-7.

10. Teo MK, Mathieson C, Carruthers R, Stewart W, Alakandy L. Cauda equina lymphoma--a rare presentation of primary central nervous system lymphoma: case report and literature review. Br J Neurosurg. 2012;26:868-71.

11. Tomita N, Kodama F, Sakai R, Koharasawa H, Hattori M, Taguchi J, Fujita H, Tanabe J, Fujisawa S, Fukawa H, Harano H, Kanamori H, Miyashita H, Matsuzaki M, Ogawa K, Motomura S, Maruta A, Ishigatsubo Y. Predictive factors for central nervous system involvement in non-Hodgkin's lymphoma: significance of very high serum LDH concentrations. Leuk Lymphoma. 2000;38:335-43.

12. Hollender A, Kvaloy S, Lote K, Nome O, Holte H. Prognostic factors in 140 adult patients with non-Hodgkin's lymphoma with systemic central nervous system (CNS) involvement. A single Centre analysis. Eur J Cancer. 2000;36:1762-8.

13. Ribrag V, Bibeau F, El WA, Frayfer J, Fadel C, Cebotaru C, Laribi K, Fenaux P. Primary breast lymphoma: a report of 20 cases. $\mathrm{Br} J$ Haematol. 2001;115:253-6.

14. van Besien K, Ha CS, Murphy S, McLaughlin P, Rodriguez A, Amin K, Forman A, Romaguera J, Hagemeister F, Younes A, Bachier C, Sarris A, Sobocinski KS, Cox JD, Cabanillas F. Risk factors, treatment, and outcome of central nervous system recurrence in adults with intermediate-grade and immunoblastic lymphoma. Blood. 1998;91:1178-84.

15. Schmitz N, Zeynalova S, Loeffler M, Pfreundschuh M. Response: intrathecal methotrexate and central nervous system events. Blood. 2009;114:1999-2000

16. Flanagan EP, O'Neill BP, Porter AB, Lanzino G, Haberman TM, Keegan BM. Primary intramedullary spinal cord lymphoma. Neurology. 2011;77:784-91.
17. Suzuki K, Yasuda T, Hiraiwa T, Kanamori M, Kimura T, Kawaguchi Y. Primary cauda equina lymphoma diagnosed by nerve biopsy: a case report and literature review. Oncol Lett. 2018;16:623-31.

18. Kinoshita $H$, Yamakado $H$, Kitano $T$, Kitamura A, Yamashita H, Miyamoto M, Hitomi T, Okada T, Nakamoto Y, Sawamoto N, Takaori-Kondo A, Takahashi R. Diagnostic utility of FDG-PET in neurolymphomatosis: report of five cases. J Neurol. 2016;263:1719-26.

\section{Publisher's Note}

Springer Nature remains neutral with regard to jurisdictional claims in published maps and institutional affiliations.
Ready to submit your research? Choose BMC and benefit from:

- fast, convenient online submission

- thorough peer review by experienced researchers in your field

- rapid publication on acceptance

- support for research data, including large and complex data types

- gold Open Access which fosters wider collaboration and increased citations

- maximum visibility for your research: over $100 \mathrm{M}$ website views per year

At $\mathrm{BMC}$, research is always in progress.

Learn more biomedcentral.com/submissions 